\title{
Editorial: Copyright and related rights and library and information services
}

\section{Introduction}

The core function of all library and information services is to provide access to the products of human intellectual and creative endeavours. The roles of library and information services differ depending on the needs to their communities supporting learning, corporate decision making, preservation of the cultural heritage, or leisure activities - but what they all have in common is that their services are built around intellectual property and they have to operate within legal frameworks, particularly copyright laws.

While library and information services have a major part to play in facilitating access to information, in some ways they are in competition with intellectual property rights holders. For example, lending of copyright works is an act restricted to the rights holder and so library and information services can only operate lawfully under copyright exceptions and special arrangements, such as public lending right in the United Kingdom. The same is true of other services provided by libraries such as the provision of copying and printing facilities and services and accessible copies of copyright works. Collection and preservation of library collections often involves restricted acts, including copying, adapting and making collections available digitally and remotely.

This special issue focuses on copyright and related rights issues in library and information services in the UK and worldwide. This theme is timely given recent changes to UK copyright law and legal and policy developments in other jurisdictions that have an impact on library and information services. A call for papers on this topic was issued in Spring 2015. Suggested topics were:

- The impact recent policy or legislative changes have had on library policies, procedures and practice;

- Aspects of copyright and related rights laws that adversely affect the ability of LIS to provide access to information;

- Examples of LIS and rights holders collaboration;

- Examples of LIS educating and supporting their communities in accessing, using and disseminating information through copyright exceptions and licensing;

- International comparisons and examples of international cooperation; and

- Ethical issues related to copyright, IP and LIS.

In response we received a number of submissions, including opinion pieces, reports and research articles from practitioners and researchers based in the UK, Ireland and Australia. 


\section{The papers}

The papers included in this special issue as a whole address aspects of all of the suggested topics. Two papers focused on the legal frameworks, including changes to the law and remaining challenges presented by current frameworks. Two papers focused on development of policy and procedures within library and information services. The related issues of copyright literacy of information professionals and the copyright adviser role within library and information services are addressed in a further two papers. The papers included in this issue cover a range of contexts and library sectors, particularly academic libraries, law libraries and a national digital repository.

Ruth MacMullen addresses copyright and the provision of accessible resources in her opinion piece. This piece focuses on the practical implications of the new UK Copyright and Rights in Performances (Disability) Regulations 2014, comparing the changes to previous provisions, how the Regulations work alongside collective licensing arrangements and identifying barriers to realising the benefits of changes. Legislative change in the UK is placed within the broader international context and the need for cooperation to facilitate the creation of accessible copies is identified.

Lisa Peters and Craig Smith report on the policy and procedures for providing accessible textbooks to students by a UK university library service, working within the relevant legal frameworks and in cooperation with publishers. This report describes practical difficulties of obtaining accessible copies and the role of the Royal National Institute of Blind People Load2Learn service in helping libraries support "print-impaired" learners.

Rebecca Grant, Sharon Webb and Marta Bustillo discuss the approach taken to consider copyright issues in the context of the development of the Digital Repository of Ireland trusted repository of humanities and social science data. The project consortium established a Copyright and IP Taskforce (CIPT) to communicate intellectual property-related issues and challenges to the project stakeholders and to ensure that policy and the infrastructure comply with relevant legal frameworks. This paper provides a detailed account of how the Taskforce went about its work and the framework that was developed to address the legal issues identified. A development of particular relevance to this project was the European Union Directive on Orphan Works. This paper also describes the impact of this legal change on a demonstrator project involving archival material relating to a stained glass business.

Aislinn O'Connell's paper also addresses orphan works and a provision in UK copyright law that means some unpublished works will remain in copyright until 2039 regardless of when they were created. While the EU Directive on orphan works provides some support to stewardship institutions in preserving and making works available, the UK government has declined to change the transitional arrangements made for copyright terms for unpublished works at the last major overhaul of UK copyright law in the 1980s. This paper proposes and evaluates various alternative approaches that cultural and heritage institutions could take to making affected works available and concludes that the current arrangements should be simplified. 
Louise Carson and Kathryn Greenhill discuss their research on the role of copyright officers in university libraries in Western Australia. They identify two models for this role, depending on whether the role is solely or only partly focused on copyright issues. The research involved detailed discussions with library staff currently in this role. The discussions focussed on the nature of the role, in the library and wider institution, and on the support for copyright officers and compliance from the institution.

Chris Morrison and Jane Secker carried out a survey of levels of copyright literacy amongst UK library, information and cultural heritage sector professionals and those who work in the cultural heritage sector. The majority of responses came from the higher education sector. While the results of the survey showed that this is higher in UK professionals and institutions compared with an earlier survey of other countries, the research also explored education and training needs. Based on the research the authors have suggested that educational programmes should be embedded in training of professionals, but also identify the need for further research to deepen and broaden understanding of copyright literacy of both LIS and other professionals within the higher education sector.

\section{Conclusions}

The papers submitted for this special confirm that copyright is an important issue in library and information services. It is an issue that information professionals are dealing with directly in the provision of services. Information professionals are also playing a role in supporting their institutional community in complying with copyright law. There have been various changes to copyright laws in the European Union aimed at improving access to information and these have been welcomed by the profession. However, there are still challenges in implementing policies and procedures and working with rights holders and the need for further legal reform is highlighted.

\section{Adrienne Muir}

\section{Open access and copyright}

Library and Information Research is an open access journal. A freely available copy of this paper may be downloaded from the journal's website: http://www.lirgjournal.org.uk.

Copyright and associated moral rights in works published in Library and Information Research are retained by the author(s) but this paper may be used freely, with proper attribution, in educational and other non-commercial settings. 